\title{
Photoprotective Mechanisms of 'Concord' Grape Leaves in Relation to Iron Supply
}

\author{
Brandon R. Smith and Lailiang Cheng 1 \\ Department of Horticulture, Cornell University, Ithaca, NY 14853
}

\begin{abstract}
AdDitional INDEX wORDs. active Fe, xanthophyll cycle, thermal dissipation, antioxidants, oxidative stress, chlorophyll fluorescence, Fe deficiency, chlorosis, Vitis labruscana Bailey

Abstract. The objective of this study was to quantify how photoprotective mechanisms in the leaves of 'Concord' grapevines (Vitis labruscana Bailey) respond to a range of iron (Fe) supply. Own-rooted, 1-year-old container-grown vines were fertigated twice weekly for 11 weeks with a complete nutrient solution containing $1,10,20,50$, or $100 \mu \mathrm{M} \mathrm{Fe}$ from ferric ethylenediamine di (o-hydroxyphenylacetic) acid (Fe-EDDHA). Leaf total Fe content did not increase in response to Fe supply; however, "active" Fe (extracted with 2,2'-dipyridyl) and chlorophyll (Chl) increased on a leaf area basis as applied Fe increased. At the lowest active Fe level, leaf absorptance and the efficiency of excitation transfer $\left(F_{v}{ }^{\prime} / F_{m}{ }^{\prime}\right)$ was lower, and nonphotochemical quenching (NPQ) was significantly greater. Photosystem II (PSII) quantum efficiency decreased curvilinearly, and the proportion of PSII reaction centers in the open state $(q \mathrm{P})$ decreased linearly as active Fecontent decreased. On a Chl basis, the xanthophyll cycle pool size [violaxanthin (V) + antheraxanthin (A) + zeaxanthin (Z)], lutein, and $\beta$-carotene increased curvilinearly as active Fe decreased, and neoxanthin (Neo) increased at the lowest Fe level. On a leaf area basis, as active Fe decreased, $V+A+Z$ and $\beta$-carotene decreased curvilinearly, and lutein and Neo decreased linearly. At noon, conversion of $\mathrm{V}$ to $\mathrm{A}$ and $\mathrm{Z}$ increased as active Fe decreased. On a Chl basis, activities of antioxidant enzymes superoxide dismutase (SOD), monodehydroascorbate reductase (MDAR), and dehydroascorbate reductase (DHAR) increased curvilinearly, and glutathione reductase (GR) activity increased linearly as active Fe levels declined. Ascorbate peroxidase (APX) and catalase (CAT), on a Chl basis, were relatively constant. On a leaf area basis, a decrease in active Fe increased SOD and MDAR activity, whereas APX, CAT, DHAR and GR activity decreased. Antioxidant metabolites ascorbate (AsA), dehydroascorbate (DAsA), reduced glutathione (GSH) and oxidized glutathione (GSSG) also increased in response to Fe limitation when expressed on a Chl basis, whereas on a leaf area basis AsA and DAsA decreased and GSH increased curvilinearly. The GSH:GSSG ratio increased as active Fe declined, whereas the AsA:DAsA ratio did not change. In conclusion, both photoprotective mechanisms, xanthophyll cycle-dependent thermal dissipation and the ascorbate-glutathione antioxidant system, are enhanced in response to Fe deficiency to cope with excess absorbed light. In a low soil pH tolerant species such as V. labruscana, the foliar antioxidant system was upregulated in response to excess absorbed light from Fe deficiency-induced chlorosis, and there was no evidence of an increase in oxidative stress from high rates of applied Fe-EDDHA.
\end{abstract}

Iron deficiency in crops is a global problem that affects plant productivity and human nutrition. Many horticultural and agronomic crops, including grapes (Vitis L.), are frequently plagued by Fe-deficiency (Chaney, 1988). Fe-deficiency induced chlorosis impacts grape production throughout Europe and the northwest United States (Tagliavini and Rombola, 2001; Davenport et al., 2003). Tolerance to Fe-deficiency varies by scion and rootstock genotype, and Vitis vinifera L. and V. berlanderi Planch. are generally less susceptible to Fe-deficiency than V. labruscana and $V$. riparia Michx. (Bavaresco et al., 2003; Tagliavini and Rombola, 2001; Winkler et al., 1974).

Fe uptake in dicotyledons and nongraminaceous monocots, so-called Strategy I plants, is typically accomplished by reducing $\mathrm{Fe}$ (III)-chelates with a root plasma membrane (PM) bound ferric chelate reductase (FCR), and transporting the liberated $\mathrm{Fe}^{2+}$ ion across the PM by $\mathrm{Fe}^{2+}$ transporters (Chaney et al., 1972; Robinson et al., 1999; Vert et al., 2002). Under severe Fe limitation, Fe-efficient plants can increase Fe solubility and uptake by increasing: 1) root $\mathrm{H}^{+}$efflux by activation of $\mathrm{H}^{+}$-ATPase, 2) root FCR activity, 3) $\mathrm{Fe}^{2+}$ transporter activity, and 4) exudation of

Received on 28 Sept. 2004. Accepted for publication 19 Nov. 2004. This work was supported in part by USDA Viticulture Consortium, New York Wine/Grape Foundation and Hatch funds. We would like to acknowledge Dr. Lisong Chen for his advice and assistance with enzyme and metabolite analyses, and to thank GreenCare Inc. for providing the nutrients used in this work.

1Corresponding author: Fax: +1-607-255-4355; email: LC89@cornell.edu
Fe(III)-chelating organic acids (Bienfait, 1987; Kochian, 1991). Fe-inefficient species generally lack, or have decreased levels of these Fe uptake mechanisms, and frequently suffer from Fechlorosis (Brown and Jones, 1976).

In the xylem, $\mathrm{Fe}$ is transported primarily as $\mathrm{Fe}(\mathrm{III})$-citrate, and FCR activity has been shown to be a requirement for uptake into mesophyll cells (Brüggemann et al., 1993; Tiffin, 1970). A high leaf apoplast $\mathrm{pH}$ is associated with Fe-deficiency in the leaves of field-grown pear trees (Pyrus communis L.) and has been found to decrease FCR activity (Gonzalez-Vallejo et al., 2000; López-Millán et al., 2001). In field-grown plants suffering from $\mathrm{Fe}$-deficiency, there is often a poor correlation between total Fe content and chlorosis, termed the "chlorosis paradox," and chlorotic leaves often contain higher total $\mathrm{Fe}$ than chlorophyllsufficient leaves. Extraction of so-called "active" Fe from leaves with $\mathrm{Fe}(\mathrm{II})$-chelators or dilute acids is often a better measure of Fe status than total Fe (Abadía et al., 1984; Chen et al., 2004).

In the leaves, $\mathrm{Fe}$ can play a pivotal role in photosynthesis and oxidative stress due to the requirement of $\mathrm{Fe}$ for chlorophyll synthesis, photosynthetic electron transport, and enzyme activation via the ferredoxin-thioredoxin system (Miller et al., 1995; Terry, 1983). Fe limitation affects the utilization of light energy due to a decrease in the number of photosynthetic units, and a reduction in light absorption (Morales et al., 2000; Spiller and Terry, 1980). Under conditions of high photon flux density $(P F D)$, the decline in photosynthetic capacity accompanying Fe-deficient leaves can lead to an excess of absorbed light (Abadía et al., 
1999). Excess absorbed PFD can then result in the production of potentially harmful reduced reactive oxygen species (ROS). High concentrations of free or loosely-bound Fe can also contribute to the production of ROS, particularly through the Fenton reaction (Halliwell and Gutteridge, 1984). In the presence of free $\mathrm{Fe}^{2+}$, the dangerous hydroxyl radical $(\cdot \mathrm{OH})$ can be produced from $\mathrm{H}_{2} \mathrm{O}_{2}$, and the resulting oxidized $\mathrm{Fe}^{3+}$ can be reduced by superoxide, promoting continuation of the reaction (Briat, 2002).

To deal with the damaging effects of excess absorbed light and the increased production of ROS, plants have developed photoprotective mechanisms (Niyogi, 2000). The two major photoprotective mechanisms are 1) singlet oxygen $\left({ }^{1} \mathrm{O}_{2}\right)$ quenching and thermal dissipation via the xanthophyll cycle, and 2) scavenging of ROS through the ascorbate-glutathione cycle. In the xanthophyll cycle, high light and a low lumen $\mathrm{pH}$ activates violaxanthin deepoxidase, which converts violaxanthin to the intermediate antheraxanthin, then to the epoxide-free zeaxanthin, both of which are able to dissipate excess excitation energy as heat (Demmig-Adams and Adams, 1996; Li et al., 2004).

During conditions that promote direct electron transfer to $\mathrm{O}_{2}$, the ascorbate-glutathione cycle becomes an important ROS scavenging system (Asada, 1999; Noctor and Foyer, 1998). In this process, the univalent reduction of $\mathrm{O}_{2}$ results in the formation of superoxide $\left(\mathrm{O}_{2}^{-}\right)$, and SOD dismutes $\mathrm{O}_{2}^{-}$to $\mathrm{O}_{2}$ and $\mathrm{H}_{2} \mathrm{O}_{2}$ (Noctor and Foyer, 1998). APX then converts $\mathrm{H}_{2} \mathrm{O}_{2}$ to $\mathrm{H}_{2} \mathrm{O}$ using AsA (Nakano and Asada, 1981), and the resulting MDA radical is reduced back to AsA in the thylakoids by ferredoxin $(\mathrm{Fd})$, or in the stroma by MDAR using reduced nicotinamide adenine dinucleotide (phosphate) (NAD(P)H) (Hossain et al., 1984; Miyake and Asada, 1994). MDA can also spontaneously disproportionate to DHA, which is reduced to AsA by DHAR using GSH (Noctor and Foyer, 1998). The resulting oxidized GSSG is then reduced by GR using $\mathrm{NAD}(\mathrm{P}) \mathrm{H}$. In addition to scavenging ROS from the direct photoreduction of $\mathrm{O}_{2}$, the ascorbate-glutathione cycle has also been shown to be upregulated under conditions of Fe-mediated oxidative stress (Kampfenkel et al., 1995).

Our objective was to quantify how photoprotective mechanisms in the leaves of 'Concord' grapevines respond to a range of Fe supply. This was accomplished by measuring xanthophyll carotenoids, chlorophyll fluorescence quenching, and enzymes and metabolites in the ascorbate-glutathione cycle.

\section{Materials and Methods}

Plant culture and Fe treatments. A detailed experimental design was described in Chen et al. (2004). Briefly, own-rooted 1-year-old 'Concord' grapevines pruned to one shoot were grown outdoors in 19.8-L plastic containers, using a commercially blended medium (MetroMix 560 with Coir; Scotts Co., Marysville, Ohio). There were five replicate plants per Fe treatment in a completely randomized design. Eleven weeks after transplanting, recent fully expanded leaves were chosen for analysis.

Each plant was supplied twice weekly with $1 \mathrm{~L}$ of a complete nutrient solution including micronutrients, and 1, 10, 20, 50, or $100 \mu \mathrm{M}$ Fe from Fe(III)-EDDHA. Macronutrients were from a blended water-soluble fertilizer $(17 \mathrm{~N}-2.2 \mathrm{P}-14.1 \mathrm{~K}-3 \mathrm{Ca}-1 \mathrm{Mg}$; GreenCare Fertilizers, Chicago) and were applied at a concentration of $16 \mathrm{~mm} \mathrm{~N}, 0.9 \mathrm{~mm}$ P, $4.5 \mathrm{~mm} \mathrm{~K}, 0.9 \mathrm{~mm} \mathrm{Ca}$, and $0.5 \mathrm{~mm}$ $\mathrm{Mg}$. Micronutrients were applied at a concentration of $10 \mu \mathrm{M} \mathrm{Mn}$ $\left(\mathrm{MnSO}_{4} \cdot \mathrm{H}_{2} \mathrm{O}\right), 2 \mu \mathrm{M} \mathrm{Zn}\left(\mathrm{ZnSO}_{4} \cdot 7 \mathrm{H}_{2} \mathrm{O}\right), 0.50 \mu \mathrm{M} \mathrm{Cu}\left(\mathrm{CuSO}_{4} \cdot 5\right.$ $\left.\mathrm{H}_{2} \mathrm{O}\right), 25 \mu \mathrm{M} \mathrm{B}\left(\mathrm{H}_{3} \mathrm{BO}_{3}\right)$, and $0.50 \mu \mathrm{M} \mathrm{Mo}\left(\mathrm{NaMoO}_{4}\right)$. The mean $\mathrm{pH}$ of the medium was $6.6 \pm 0.1$.
LEAF ABSORPTANCE AND CHLOROPHYLL FLUORESCENCE. Leaf reflectance and transmittance was measured with a LI-1800 spectroradiometer, using an 1800-12S integrating sphere attachment (LI-COR, Lincoln, Neb.) as described in Cheng et al. (2000). Leaf absorptance was calculated as 1-reflectance-transmittance.

Chlorophyll fluorescence was measured with a pulse-modulated fluorometer (FMS2; Hansatech Instruments, Norfolk, U.K.) under natural conditions, either at a midday $P F D$ of $1805 \pm 20$ $\mu \mathrm{mol} \cdot \mathrm{m}^{-2} \cdot \mathrm{s}^{-1}$, or at predawn. The fibre optic of the FMS2 was positioned using the $P F D /$ temperature leaf clip at a $60^{\circ}$ angle from the upper surface of the leaf, and the distance between the fiber optic and the leaf surface was kept constant for both the predawn and the midday measurements. Dark-adapted leaves were measured at predawn for minimum fluorescence $\left(F_{\mathrm{o}}\right)$ and maximum fluorescence $\left(F_{\mathrm{m}}\right)$. During midday measurements, stable steady-state fluorescence $\left(F^{\prime}\right)$ readings were obtained before further measurements were taken. Maximum fluorescence $\left(F_{\mathrm{m}}{ }^{\prime}\right)$ under natural light exposure was obtained by imposing a $1 \mathrm{~s}$ saturating flash of $\approx 6000 \mu \mathrm{mol} \cdot \mathrm{m}^{-2} \cdot \mathrm{s}^{-1} P F D$ at the leaf surface to reduce all PSII centers. Minimal fluorescence $\left(F_{0}{ }^{\prime}\right)$ was calculated according to Oxborough and Baker (1997) as: $F_{\mathrm{o}}{ }^{\prime}=$ $F_{\mathrm{o}} /\left(\left(F_{\mathrm{v}} / F_{\mathrm{m}}\right)+\left(F_{\mathrm{o}} / F_{\mathrm{m}}{ }^{\prime}\right)\right)$. The maximum PSII efficiency of darkadapted leaves was calculated as $F_{\mathrm{v}} / F_{\mathrm{m}}=\left(F_{\mathrm{m}}-F_{\mathrm{o}}\right) / \mathrm{F}_{\mathrm{m}}$ (van Kooten and Snel, 1990). Thermal energy dissipation was estimated from nonphotochemical quenching (NPQ) as $F_{\mathrm{m}} / F_{\mathrm{m}}{ }^{\prime}-1$ (Bilger and Bjorkman, 1990). Efficiency of excitation transfer, $F_{\mathrm{v}}{ }^{\prime} / F_{\mathrm{m}}$ ', was calculated as $\left(F_{\mathrm{m}}{ }^{\prime}-F_{\mathrm{o}}{ }^{\prime}\right) / F_{\mathrm{m}}{ }^{\prime}$, the photochemical quenching coefficient ( $q \mathrm{P}$, related to the proportion of PSII centers in "open" state) was estimated as $\left(F_{\mathrm{m}}{ }^{\prime}-F^{\prime}\right) /\left(F_{\mathrm{m}}{ }^{\prime}-F_{\mathrm{o}}{ }^{\prime}\right)$ (Baker et al., 2001), and the PSII quantum efficiency (similar notation, ФPSII) was calculated as $\left(F_{\mathrm{m}}{ }^{\prime}-F^{\prime}\right) / F_{\mathrm{m}}{ }^{\prime}$ (Genty et al., 1989).

ANALYSIS OF LEAF PIGMENTS. Immediately before midday Chl fluorescence measurements, disks $\left(1 \mathrm{~cm}^{2}\right.$ in size) were punched from the leaves and frozen in liquid $\mathrm{N}_{2}$. Frozen leaf disks were stored at $-80{ }^{\circ} \mathrm{C}$ until analysis of leaf pigments. V, A, Z, Neo, lutein, and $\beta$-carotene were extracted from one leaf disk $\left(1 \mathrm{~cm}^{2}\right)$ and analyzed by high-performance liquid chromatography (HPLC) following the same procedure described by Cheng (2003). Leaf Chl was extracted and measured according to Arnon (1949).

EXTRACTION AND ASSAY OF ANTIOXIDANT ENZYMES AND METABOLITES. Antioxidant enzymes, and AsA and DAsA, were measured as described by Chen and Cheng (2003). GSH and GSSG were determined according to Griffith (1980), with some modifications. Two leaf disks (total of $2 \mathrm{~cm}^{2}$ ) were ground in $1 \mathrm{~mL}$ ice-cold $5 \%$ $(\mathrm{w} / \mathrm{v})$ trichloroacetic acid (TCA) and 5\% (w/v) insoluble polyvinylpolypyrrolidone. Extract was centrifuged at $13,000 g_{\mathrm{n}}$ for 10 min at $2{ }^{\circ} \mathrm{C}$, and the supernatant was centrifuged again under the same conditions. The resulting supernatant was used for analysis. Total GSH was determined at $412 \mathrm{~nm}$ in a $1-\mathrm{mL}$ reaction mixture containing $150 \mathrm{~mm}$ sodium phosphate buffer $(\mathrm{pH} 6.9), 6.3 \mathrm{~mm}$ EDTA, 1.2 mm 5,5'-Dithiobis(2-nitrobenzoic acid) (DTNB), 0.2 mM NADPH, 0.5 units GR (Sigma-Aldrich, St. Louis), and 20 $\mu \mathrm{L}$ plant extract. The reaction was initiated with the addition of GR. To determine GSSG, $20 \mu \mathrm{L}$ of plant extract was incubated in $20 \mu \mathrm{L} 2$-vinylpyridine for $1 \mathrm{~h}$ to completely derivatize all GSH. GSSG was then assayed as above. Both GSH and GSSG were measured against an internal standard of $10 \mu \mathrm{M}$ GSSG, and final concentration was determined from a standard curve of GSSG.

IrON ANALYSIS. Active Fe was assayed according to Abadía et al. (1984) as described by Chen et al. (2004). Three $1-\mathrm{cm}^{2}$ disks were shaken for $24 \mathrm{~h}$ in $1.2 \mathrm{~mL}$ of $80 \mathrm{~mm} 2,2^{\prime}$-dipyridyl- $\mathrm{HCl}(\mathrm{pH}$ 3.0 ) in $10 \%$ methanol. Extract was passed through a $0.45-\mu \mathrm{m}$ 
syringe filter and $1 \mathrm{~mL}$ of solution was assayed at $522 \mathrm{~nm}$. Total Fe was measured from dried leaves using an inductively coupled plasma emission spectrometer (model 975, Plasma Atomcomp; Thermo Jarrell Ash Corp., Franklin, Mass.).

\section{Results}

Foliar Fe AND FRESH MASS. An increase in Fe application rate did not increase leaf total Fe content (Fig. 1A). Active Fe extracted from the fresh leaves, however, rose curvilinearly as nutrient solution Fe levels increased (Fig. 1B). The leaf specific fresh mass increased curvilinearly as active Fe content increased, but lacked a relationship with total $\mathrm{Fe}$ content (data not shown).

TOTAL CHLOROPHYLL AND LEAF ABSORPTANCE. Total chlorophyll was closely related to leaf active Fe content (Fig. 2A), yet showed no relationship to total Fe content (data not shown). Leaf absorptance declined curvilinearly as active Fe decreased (Fig. 2B), with only small differences at the higher active Fe levels. Leaf absorptance decreased the most from the second to the lowest active Fe level, from $90.7 \%$ to $83.3 \%$.

XANTHOPHYLL CYCLE, LUTEIN, $\beta$-CAROTENE, AND NEOXANTHIN. On a leaf area basis, the xanthophyll pool size $[\mathrm{V}+\mathrm{A}+\mathrm{Z}]$ and $\beta$ carotene decreased curvilinearly, and lutein and Neo decreased linearly as active Fe decreased (Fig. 3A-D). When expressed on a leaf $\mathrm{Chl}$ basis, $\mathrm{V}+\mathrm{A}+\mathrm{Z}$ and lutein increased curvilinearly and $\beta$-carotene increased linearly as active Fe levels declined (Fig. $3 \mathrm{E}-\mathrm{G}$ ). Neoxanthin was higher only at the lowest Fe level (Fig. $3 \mathrm{H})$ when expressed on a leaf $\mathrm{Chl}$ basis.

At noon, the amount of $\mathrm{A}+\mathrm{Z}$ on a $\mathrm{Chl}$ basis increased as active Fe content decreased (Fig. 4A). The percentage of the xanthophyll pool present as $\mathrm{A}+\mathrm{Z}$ decreased linearly from $97 \%$ to $88 \%$ as active Fe content decreased from 1.43 to $2.54 \mathrm{mg} \cdot \mathrm{m}^{-2}$ (Fig. 4B). At predawn, the majority of the xanthophyll cycle pool was present
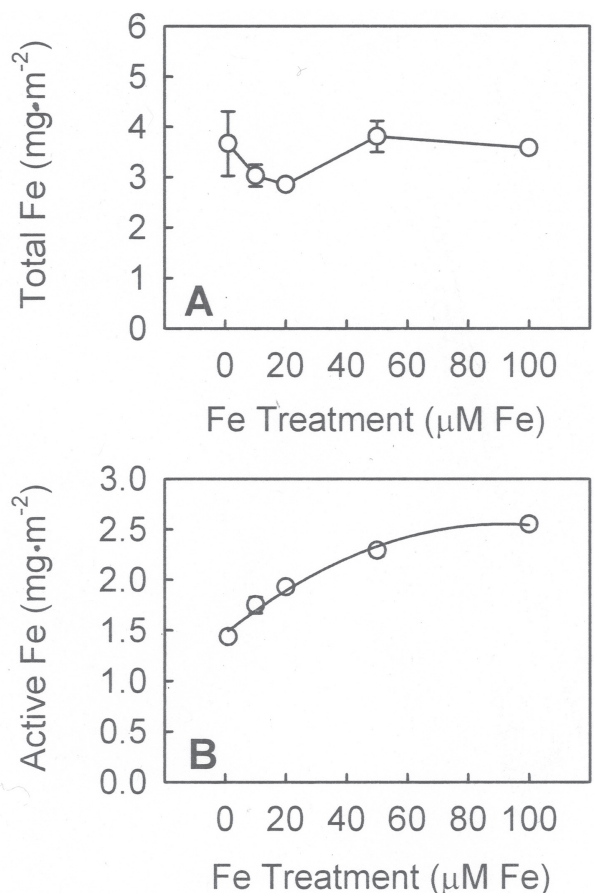

Fig. 1. Effect of iron (Fe) supply on total $\mathrm{Fe}(\mathbf{A})$ and active $\mathrm{Fe}(\mathbf{B})$ content of grape leaves. Each point is mean $\pm \mathrm{SE}(\mathrm{n}=5)$. Analysis of variance for $(\mathbf{A})$ $P>0.05$, and regression equation for $(\mathbf{B}) y=1.4685+0.0237 x-0.0001 x^{2}\left(r^{2}\right.$ $=0.987, P<0.05)$.
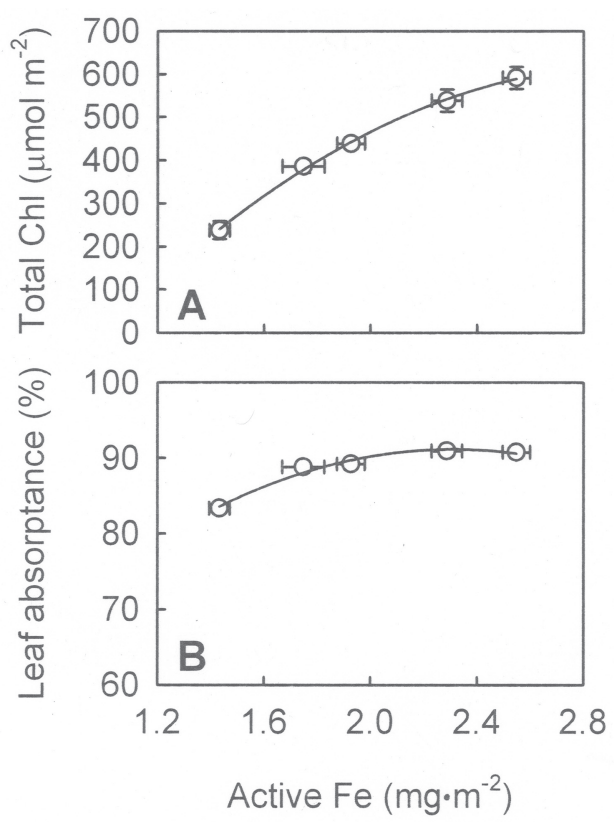

Fig. 2. Total chlorophyll (Chl) content (A) and leaf absorptance (B) of grape leaves in relation to active $\mathrm{Fe}$ content. Each point is mean \pm standard error ( $\mathrm{n}$ = 5). Regression equations for (A) $y=-768.7495+925.0537 x-153.9393 x^{2}$ $\left(r^{2}=0.999, P<0.01\right)$; and (B) $y=38.6244+45.4246 x-9.8228 x^{2}\left(r^{2}=0.975\right.$, $P<0.05)$.

as $\mathrm{V}$, and the percentage of $\mathrm{A}+\mathrm{Z}$ in the xanthophyll pool ranged from $25 \%$ at the lowest active Fe level to $19 \%$ at the highest active Fe level (data not shown).

Chlorophyll Fluorescence variables. At the lowest active Fe level, NPQ was greater, and $F_{\mathrm{v}}{ }^{\prime} / F_{\mathrm{m}}{ }^{\prime}$ was lower (Fig. $5 \mathrm{~A}$ and B). As active Fe decreased, $q \mathrm{P}$ decreased linearly and the PSII quantum efficiency increased curvilinearly (Fig. $5 \mathrm{C}$ and D). Maximum PSII efficiency decreased only slightly at the lowest active Fe level (Fig. 5E).

Relationship BETWEen XaNTHOPHYLl CyCle and Chl FluoRESCENCE VARIABLES. At midday, NPQ did not increase as leaf $\mathrm{A}+\mathrm{Z}$ content on a Chl basis increased, except at the $\mathrm{A}+\mathrm{Z}$ content of $361 \mathrm{mmol} \cdot \mathrm{mol}^{-1} \mathrm{Chl}$, there was a significant increase in NPQ (Fig. 6A). A similar trend was found when NPQ was plotted against midday $\mathrm{A}+\mathrm{Z} / \mathrm{V}+\mathrm{A}+\mathrm{Z}$, where $\mathrm{NPQ}$ was greater only at the highest percentage of $\mathrm{A}+\mathrm{Z} / \mathrm{V}+\mathrm{A}+\mathrm{Z}$ (data not shown). $F_{\mathrm{v}}{ }^{\prime} / F_{\mathrm{m}}{ }^{\prime}$ decreased curvilinearly, and qP and PSII quantum efficiency decreased linearly as leaf $\mathrm{A}+\mathrm{Z}$ content on a Chl basis increased (Fig. 6B-D).

ANTIOXIDANT ENZYMES AND METABOLITES. On a leaf area basis, SOD and MDAR activity increased, whereas the activity of APX, CAT, DHAR and GR decreased as leaf active Fe decreased (Fig. 7A-F). On a Chl basis, SOD, MDAR, and DHAR activity increased curvilinearly, and GR activity increased linearly as active Fe levels declined (Fig. 7 G, J, K, and L). APX and CAT activity, when calculated on a Chl basis, were relatively constant (Fig. 7H-I).

Total AsA (AsA+DAsA), AsA, and DAsA decreased on a leaf area basis as active Fe declined, whereas GSH increased curvilinearly and GSSG remained relatively constant (Fig. 8A-E). On a Chl basis, total AsA, AsA, DAsA, GSH, and GSSG all increased curvilinearly as active Fe levels decreased (Fig. 8G-K). The ratio of AsA/DAsA remained constant across active Fe content, however the GSH/GSSG ratio increased as active Fe decreased (Fig. $8 \mathrm{~F}$ and L) 

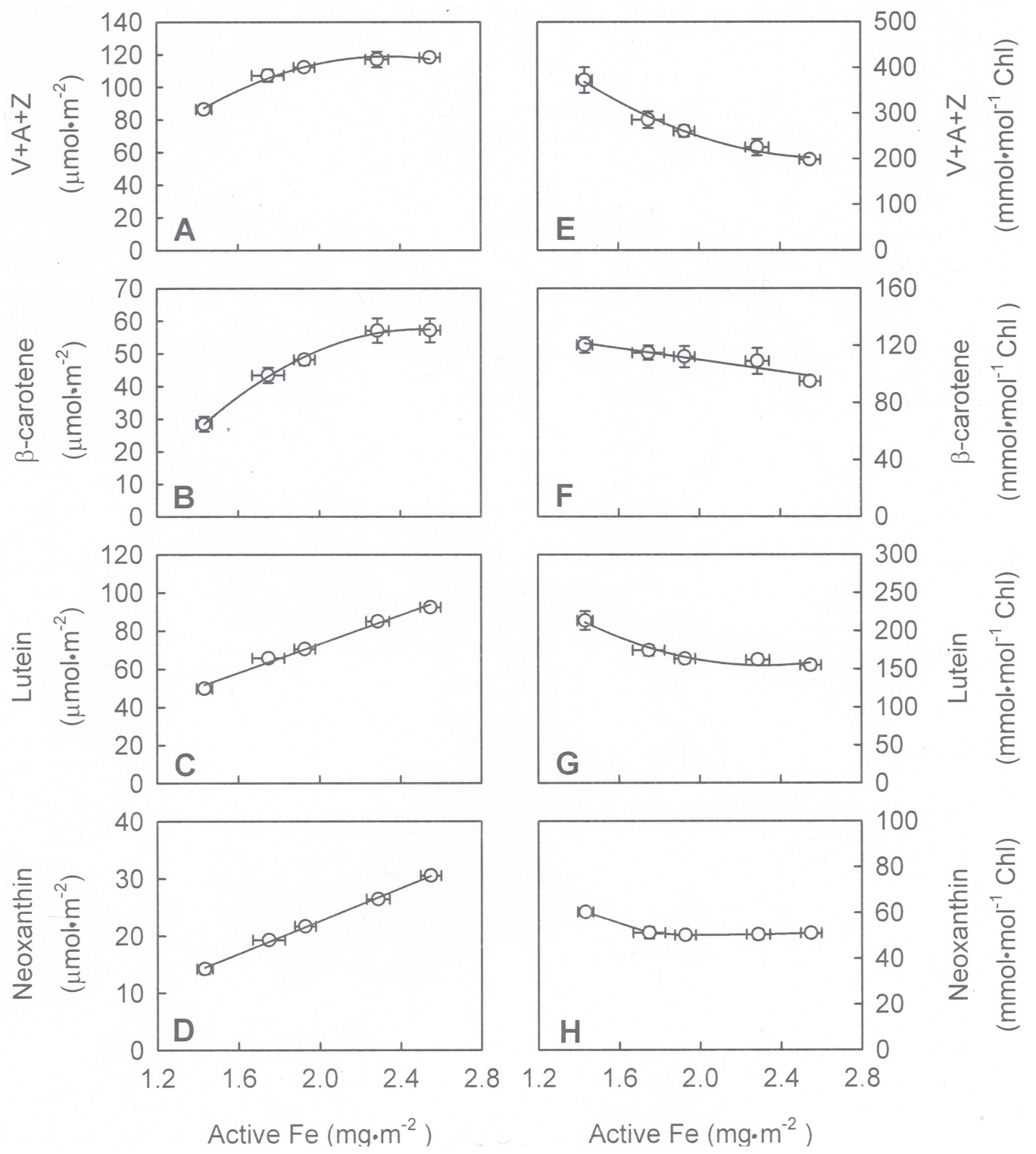

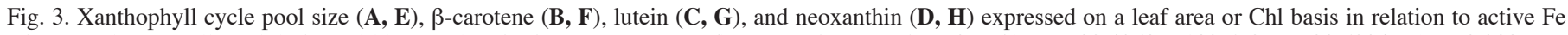

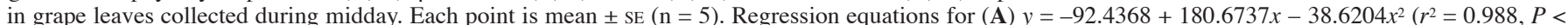

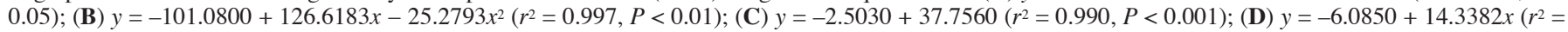

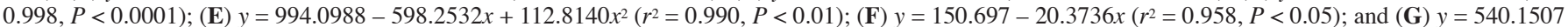

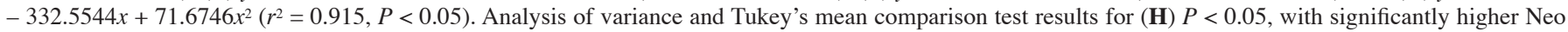
at the lowest active Fe level.

\section{Discussion}

'Concord' grape leaves developed chlorosis under Fe-limitation, however leaf total Fe did not decrease. This observation is in line with the "chlorosis paradox" phenomenon, where chlorotic leaves can often contain higher total Fe than green leaves (Römheld, 2000). Extraction of active Fe, or the loosely bound fraction of Fe, from the leaves with the Fe(II)-chelate 2,2'-dipyridyl was a better indicator of Fe nutritional status (Fig. 1B and 2A).

The possible physiological mechanism that led to chlorosis paradox observed in this experiment was discussed in detail by Chen et al (2004). Briefly, under adequate Fe-EDDHA supply conditions, most of the Fe taken up by the roots might be translocated as the $\mathrm{pH}$-stable Fe-EDDHA and thus not immobilized by high apoplast $\mathrm{pH}$. At lower Fe-EDDHA application rates, however, absorption of the Fe-EDDHA complex may not have been enough to satisfy the demand for $\mathrm{Fe}$, and the roots most likely have employed Fe-efficiency mechanisms to increase $\mathrm{Fe}$ uptake from the growing medium. As most $\mathrm{Fe}$ is transported to the mesophyll cells as Fe(III)-citrate under low Fe-EDDHA supply, a high leaf apoplast $\mathrm{pH}$ may have inhibited mesophyll FCR activity required for the reductive assimilation of $\mathrm{Fe}$ from $\mathrm{Fe}$ (III)-citrate complexes, resulting in Fe deficiency in leaves.

Fe-deficiency did reduce leaf absorptance, but the changes were not proportional to the decrease in active Fe (Fig. 2B). Considering that there was a greater decrease in $\mathrm{CO}_{2}$ assimilation rate relative to the decrease in leaf absorptance under Fe-deficiency (Chen et al., 2004), changes in leaf absorptance alone were not sufficient for photoprotection during high $P F D$, and excess absorbed light resulted. In grape leaves with nitrogen deficiency induced chlorosis, similar small decreases in leaf absorptance were found (Chen and Cheng, 2003). 

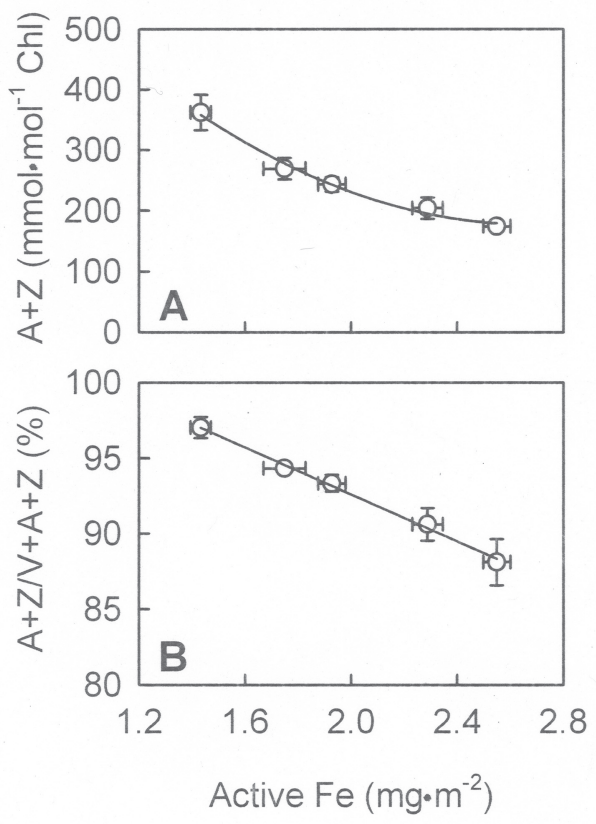

Fig. 4. Midday antheraxanthin and zeaxanthin $(A+Z)$ on a Chl basis $(\mathbf{A})$ and as a percentage of the xanthophyll cycle pool (B) of grape leaves in relation to active Fe. Each point is mean \pm SE $(\mathrm{n}=5)$. Regression equations for $(\mathbf{A})$ $y=1015.0860-626.4721 x+117.0711 x^{2}\left(r^{2}=0.990, P<0.01\right)$; and $(\mathbf{B}) y=$ $108.1826-7.7971 x\left(r^{2}=0.996, P<0.001\right)$.

Thermal dissipation of excess excitation energy, measured as $N P Q$, was increased only at the lowest active Fe level (Fig. $5 \mathrm{~A})$, even though chlorophyll content decreased nearly linearly from $591 \mu \mathrm{mol} \cdot \mathrm{m}^{-2}$ at the highest active Fe level to $238 \mu \mathrm{mol} \cdot \mathrm{m}^{-2}$ at the lowest (Fig. 2A). The efficiency of excitation transfer $\left(F_{v}{ }^{\prime} / F_{m}{ }^{\prime}\right.$, Fig. 5B), however, correspondingly decreased only at the lowest active Fe level, indicating that $N P Q$ is increased to lower the efficiency of excitation transfer to the PSII reaction centers. Midday $N P Q$ in sugar beet (Beta vulgaris L.) and pear leaves did not appreciably increase in response to Fe-deficiency as consistently as $N P Q$ from $\mathrm{N}$-deficiency in grapevines and apple (Malus domestica Borkh.) (Chen and Cheng, 2003; Cheng, 2003; Morales et al., 1998, 2000). On the other hand, $N P Q$ in maize (Zea mays L.) and soybean [Glycine max (L.) Merr.] was dramatically increased when plants were grown in a nutrient solution without Fe; however, in this situation the differences in Chl content between Fe-deficient and control plants were either extreme (2.2 vs. $\left.22.4 \mathrm{~g} \cdot \mathrm{m}^{-2}\right)$ or not reported (Jiang et al., 2001, 2003). Our results illustrate that $N P Q$ is increased when Fe-deficiency induced chlorosis decreases to $238 \mu \mathrm{mol} \cdot \mathrm{m}^{-2} \mathrm{Chl}$ or 1.4 $\mathrm{mg} \cdot \mathrm{m}^{-2}$ active $\mathrm{Fe}$. Our observation that Fe-deficiency decreases photochemical quenching $(q \mathrm{P})$, and the PSII quantum efficiency of grape leaves at high $P F D$, yet only marginally effects the maximum PSII efficiency $\left(F_{v} / F_{m}\right)$ of dark-adapted leaves (Fig. $5 \mathrm{C}-\mathrm{E})$, is in agreement with findings from sugar beet and pear (Morales et al., 1998, 2000). Because PSII quantum efficiency is the product of $F_{v}{ }^{\prime} / F_{m}{ }^{\prime}$ and $q \mathrm{P}$, the observed curvilinear decrease in the PSII quantum efficiency in response to Fe limitation can ultimately be attributed to the linear decrease in the proportion of open reaction centers $(q \mathrm{P})$, as $F_{v}{ }^{\prime} / F_{m}{ }^{\prime}$ decreased only at the lowest active Fe level.

An increase in the proportion of closed reaction centers under high light (a decrease in photochemical quenching), without a corresponding decrease in $F_{v}{ }^{\prime} / F_{m}{ }^{\prime}$, will result in the transfer of excess excitation energy to $\mathrm{O}_{2}$, forming ${ }^{1} \mathrm{O}_{2}$. De-epoxidized xanthophylls
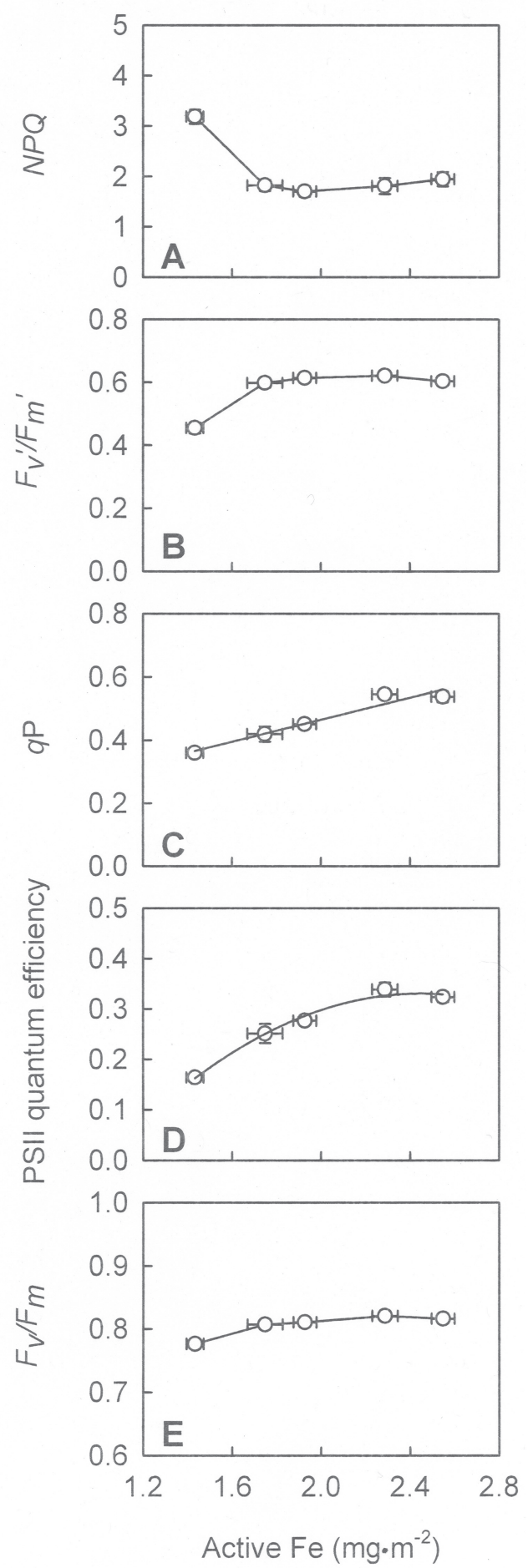

Fig. 5. Nonphotochemical quenching (NPQ) (A), efficiency of excitation transfer $\left(F_{\mathrm{v}}{ }^{\prime} / F_{\mathrm{m}}{ }^{\prime}\right)(\mathbf{B})$, photochemical quenching coefficient $(q \mathrm{P})(\mathbf{C})$, PSII quantum efficiency $(\mathbf{D})$, and maximum PSII efficiency $\left(F_{\mathrm{v}} / F_{\mathrm{m}}\right)(\mathbf{E})$ in relation to active Fe in grape leaves. Each point is mean \pm SE $(n=5)$. Regression equations for (C) $y=0.1165+0.1739 x\left(r^{2}=0.942, P<0.01\right)$; and (D) $y=-0.6493+0.8003 x$ $-0.1634 x^{2}\left(r^{2}=0.986, P<0.05\right)$. Analysis of variance and Tukey's mean comparison test results for $(\mathbf{A}) P<0.001$, with greater NPQ at the lowest active Fe level; (B) $P<0.001$, with lower $F_{\mathrm{v}}{ }^{\prime} / F_{\mathrm{m}}{ }^{\prime}$ at the lowest active Fe level; and (E) $P<0.001$, with lower $F_{\mathrm{v}} / F_{\mathrm{m}}$ at the lowest active Fe level.

(Aand Z), $\beta$-carotene, and lutein can protect PSII from photodamage by quenching ${ }^{1} \mathrm{O}_{2}$ and de-exciting ${ }^{3} \mathrm{Chl}$ (Niyogi, 2000; Niyogi et al., 1997). On a leaf area basis, all measured xanthophyll carotenoids in our leaves decreased in response to Fe-deficiency, with a smaller decrease in the $\mathrm{V}+\mathrm{A}+\mathrm{Z}$ pool compared to $\beta$-carotene, 

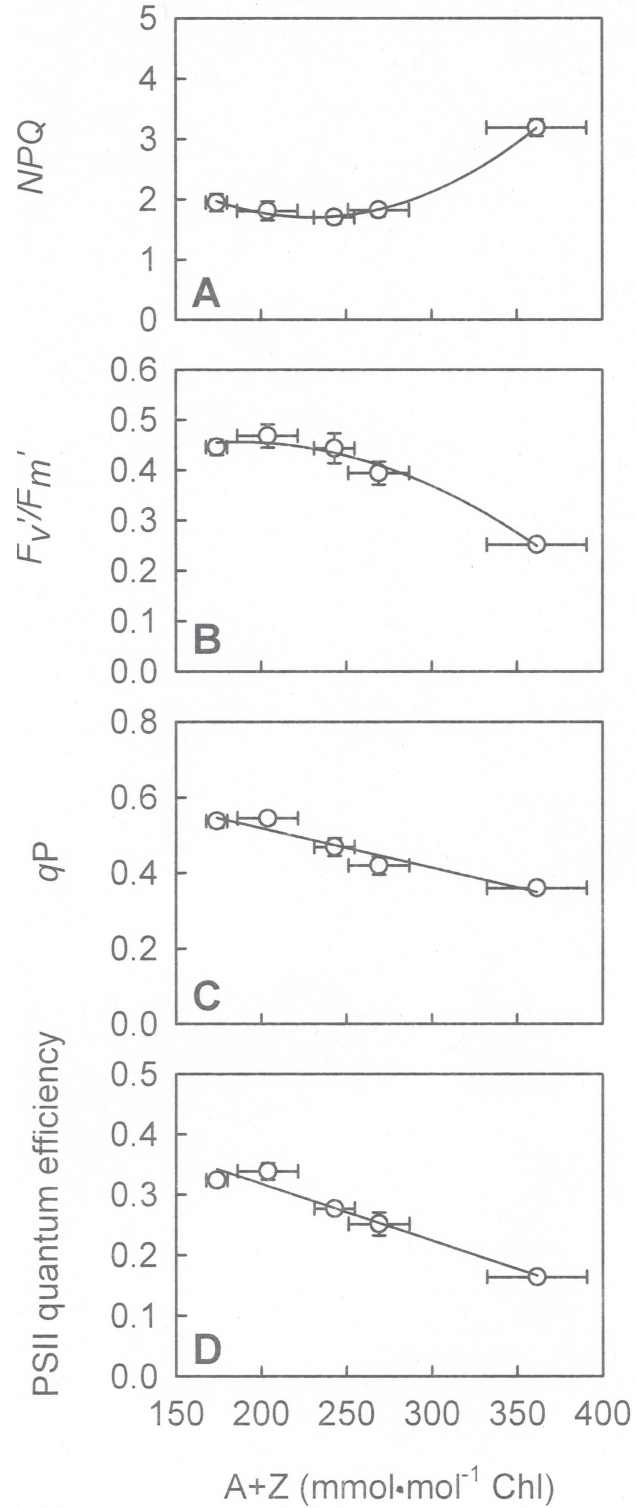

Fig. 6. Nonphotochemical quenching (NPQ) (A), efficiency of excitation transfer $\left(F_{\mathrm{v}}{ }^{\prime} / F_{\mathrm{m}}{ }^{\prime}\right)(\mathbf{B})$, photochemical quenching coefficient $(q \mathrm{P})(\mathbf{C})$, and PSII quantum efficiency $(\mathbf{D})$ in relation to the level of antheraxanthin and zeaxanthin $(A+Z)$ on a Chl basis in grape leaves at midday. Each point is mean \pm SE $(n=5)$. Regression equations for (A) $y=6.2337-0.0394 x+0.0001 x^{2}\left(r^{2}=0.998, P\right.$ $<0.01)$; (B) $y=0.2229+0.0025 x-0.0000 x^{2}\left(r^{2}=0.979, P<0.05\right)$; (C) $y=$ $0.7281-0.0010 x\left(r^{2}=0.925, P<0.01\right)$; and (D) $y=0.5056-0.0009 x\left(r^{2}=\right.$ $0.951, P<0.01)$

lutein, and Neo (Fig. 3A-D). On a Chl basis, the molar ratio of the $\mathrm{V}+\mathrm{A}+\mathrm{Z}$ pool nearly doubled ( 197 to $372 \mathrm{mmol} \cdot \mathrm{mol}^{-1} \mathrm{Chl}$ ), and $\beta$-carotene and lutein also increased as active Fe decreased from the highest active Fe level to the lowest (Fig. 3E-H). The $\mathrm{A}+\mathrm{Z}$ content on a $\mathrm{Chl}$ basis, and the percentage of the $\mathrm{V}+\mathrm{A}+\mathrm{Z}$ pool present as $\mathrm{A}+\mathrm{Z}$ (Fig. 4A-B) increased in response to Fedeficiency, indicating that xanthophyll conversion increased to dissipate excess absorbed $P F D$ in chlorotic leaves.

Similar pigment stoichiometries were also observed in moderately $\mathrm{Fe}$-deficient pear leaves, and the ratios of $\mathrm{V}+\mathrm{A}+\mathrm{Z}$ to $\mathrm{Chl}$ reached up to 1000 under conditions of severe deficiency (Chl $<50 \mu \mathrm{mol} \cdot \mathrm{m}^{-2}$ ) (Morales et al., 1994). The ratios of $\mathrm{V}+\mathrm{A}+\mathrm{Z}$ to $\mathrm{Chl}$ in response to $\mathrm{Fe}$-deficiency chlorosis are much higher than values obtained from $\mathrm{N}$-deficient grape leaves, where the $\mathrm{V}+\mathrm{A}+\mathrm{Z}$ content on a $\mathrm{Chl}$ basis reached a ratio of only $\approx 210$ at the lowest leaf Chl content $\left(\approx 200 \mu \mathrm{mol} \cdot \mathrm{m}^{-2}\right)$ (Chen and Cheng, 2003). As the $\mathrm{N}$ content of grape leaves decreased, $N P Q$ increased curvilinearly to values above 4 , and increased linearly in relation to the $A+Z$ content on a Chl basis. In the present study, an increase in the $\mathrm{A}+\mathrm{Z}$ content on a $\mathrm{Chl}$ basis was not associated with a linear increase in $N P Q$, although $N P Q$ did rise at the highest $\mathrm{A}+\mathrm{Z}$ content (Fig. $6 \mathrm{~A})$. The reason for the lack of a relationship is unclear, but if Fe availability somehow affects the transthylakoid $\mathrm{pH}$ difference or $\mathrm{PsbS}$ protein, this may alter the relationship between $\mathrm{A}+\mathrm{Z}$ and NPQ. Nonetheless, more discreet relationships were observed with increases of the $\mathrm{A}+\mathrm{Z}$ content on a $\mathrm{Chl}$ basis and decreases of PSII quantum efficiency and $q \mathrm{P}$ (Fig. 6C-D).

On a leaf $\mathrm{Chl}$ basis, activities of SOD, APX, MDAR, DHAR, and GR increased in low active Fe leaves (Fig. 7G-H, J-L). Similarly, the size of both the ascorbate and glutathione pools on a Chl basis increased as active Fe levels declined (Fig. 8G-K). The increase in these antioxidants on a $\mathrm{Chl}$ basis in low active Fe leaves indicates an upregulation of the scavenging of ROS produced from excess absorbed $P F D$. CAT activity on a Chl basis was relatively constant (Fig. 7I), and considering that most of CAT activity is localized in the peroxisomes to remove $\mathrm{H}_{2} \mathrm{O}_{2}$ from photorespiration (Willekens et al., 1995), it is not surprising that CAT did not change as a photoprotective measure.

The increase in total SOD activity on a leaf area and $\mathrm{Chl}$ basis (Fig. $7 \mathrm{~A}$ and $\mathrm{G}$ ) in response Fe-deficiency is consistent with the increased photoreduction of $\mathrm{O}_{2}$. Cu/Zn-SOD also increased in the upper leaves of Fe-deficient pea (Pisum sativum L.), but Iturbe-Ormaetxe et al. (1995) did not find an increase in $\mathrm{H}_{2} \mathrm{O}_{2}$ concentration. In Fe-deficient sunflower (Helianthus annuиs L.) leaves, however, Ranieri et al. (1999) measured an increase in both SOD activity and $\mathrm{H}_{2} \mathrm{O}_{2}$ content in tissue. Although we did not directly measure leaf $\mathrm{H}_{2} \mathrm{O}_{2}$ concentration in this study, the up-regulation of the ascorbate-glutathione cycle also suggests an increase in $\mathrm{H}_{2} \mathrm{O}_{2}$ flux in Fe-deficient leaves.

The increase in MDAR activity in response to a decrease in active $\mathrm{Fe}$ may be the result of decreased ferredoxin $(\mathrm{Fd})$-dependent reduction of MDA (Miyake and Asada, 1994) at lower active Fe contents. Fe limitation has been shown to decrease levels of the Fe-S protein Fd in citrus (Citrus limonum Risso) (Alcaraz et al., 1985). In situations where Fd content is decreased due to Fe-deficiency, MDAR activity might be up-regulated to maintain the reduction state of the ascorbate pool. In addition, the increase in the size and reduction state of the glutathione pool at lower active Fe (Fig. 8L) is consistent with a decrease in direct photoreduction of MDA by Fd. The elevated ratio of GSH to GSSG at lower active Fe was primarily due to greater GSH content, as GSSG levels remained very low and constant (Fig. 8D-E). Thus if the Fd-dependent photoreduction of MDA decreases as active Fe declines, a larger proportion of the MDA would spontaneously disproportionate to DHA, requiring an increase in the glutathione pool size (higher GSH) to reduce DHA to AsA. In response to Fe limitation, the GSH to GSSG ratio also increased in pea leaves and sugar beet roots on a dry and fresh weight basis (Iturbe-Ormaetxe et al., 1995; Zaharieva and Abadía, 2003). It appears that both reduction of MDA via MDAR and reduction of DHA via DHAR have been up-regulated under Fe deficiency, thereby maintaining a constant reduction state of the ascorbate pool (Fig. 8F).

Although an excess of catalytic $\mathrm{Fe}$ in combination with high light would be particularly detrimental to the photosynthetic apparatus, we found no evidence of Fe-toxicity visual symptoms 

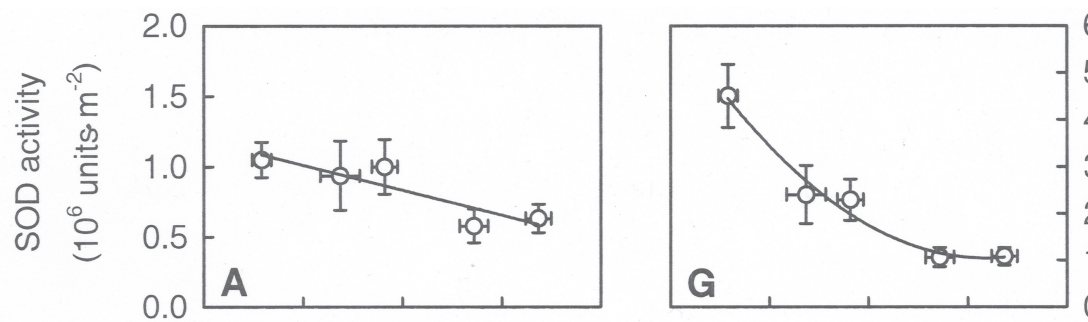

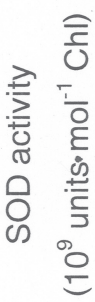
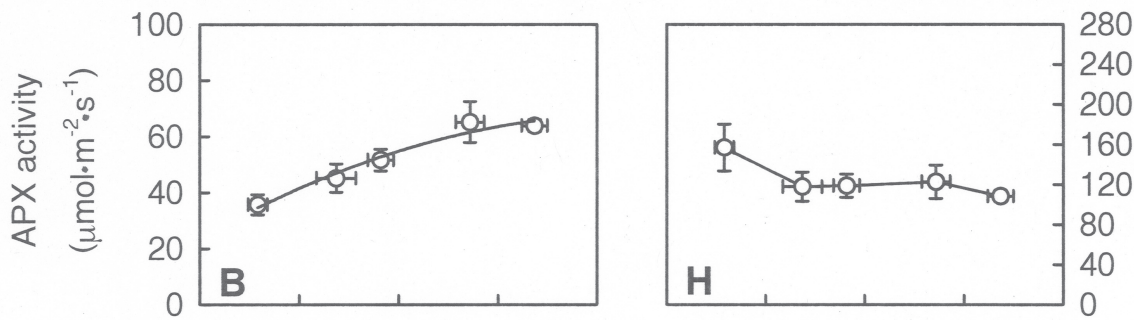

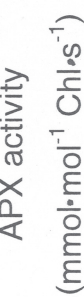
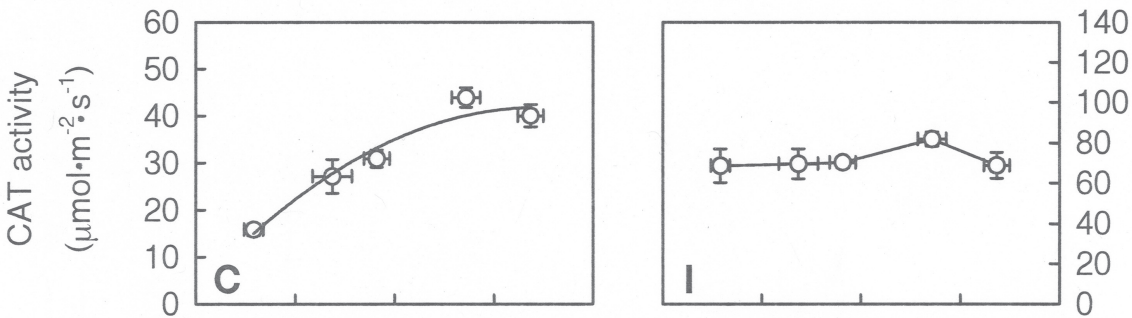

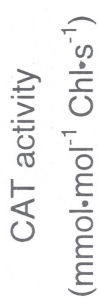
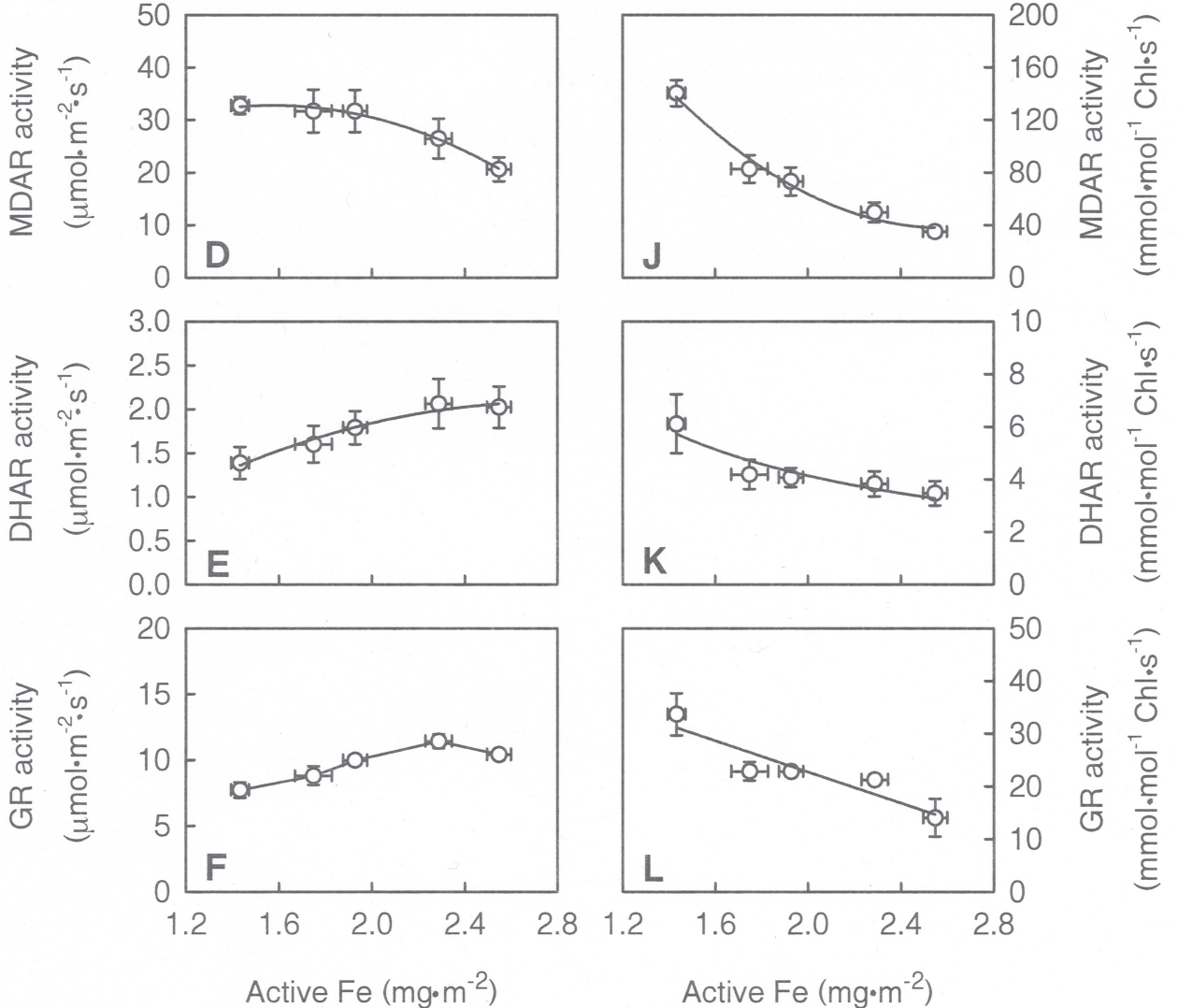

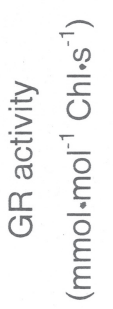

Fig. 7. Activity of antioxidant enzymes in relation to the active Fe content of grape leaves collected at midday, expressed on a leaf area or leaf Chl basis, respectively: (A, G) Superoxide dismutase (SOD); (B, H) ascorbate peroxidase (APX); (C, I) catalase (CAT); (D, J) monodehydroascorbate reductase (MDAR); (E, K) dehydroascorbate reductase (DHAR); (F, L) glutathione reductase (GR). Each point is mean \pm SE $(\mathrm{n}=5)$. Regression equations for $(\mathbf{A}) y=1.7207-0.4438 x\left(r^{2}\right.$ $=0.803, P<0.05) ;($ B $) y=-57.6935+85.0020 x-14.3703 x^{2}\left(r^{2}=0.965, P<0.05\right) ;(\mathbf{C}) y=-93.9577+105.3863 x-20.4531 x^{2}\left(r^{2}=0.952, P<0.05\right) ;(\mathbf{D}) y=$ $1.3329+39.9743 x-12.6999 x^{2}\left(r^{2}=0.992, P<0.01\right) ;(\mathbf{E}) y=-1.0398+2.2608 x-0.4099 x^{2}\left(r^{2}=0.965, P<0.05\right) ;(\mathbf{G}) y=20.2608-15.5462 x+3.1441 x^{2}\left(r^{2}=\right.$ $0.976, P<0.05)$; (H) $P>0.05$; (I) $P>0.05$; (J) $y=537.1462-385.6211 x+74.4148 x^{2}\left(r^{2}=0.983, P<0.05\right) ;(\mathbf{K}) y=0.1161+(8.0371 / x)\left(r^{2}=0.870, P<0.05\right) ;$ and $(\mathbf{L}) y=52.2771-14.7695 x\left(r^{2}=0.856, P<0.05\right)$. Analysis of variance and Tukey's mean comparison test for $(\mathrm{F}) P<0.01$, with significantly decreased GR activity at the lowest two active Fe levels vs. the second highest active Fe level. 

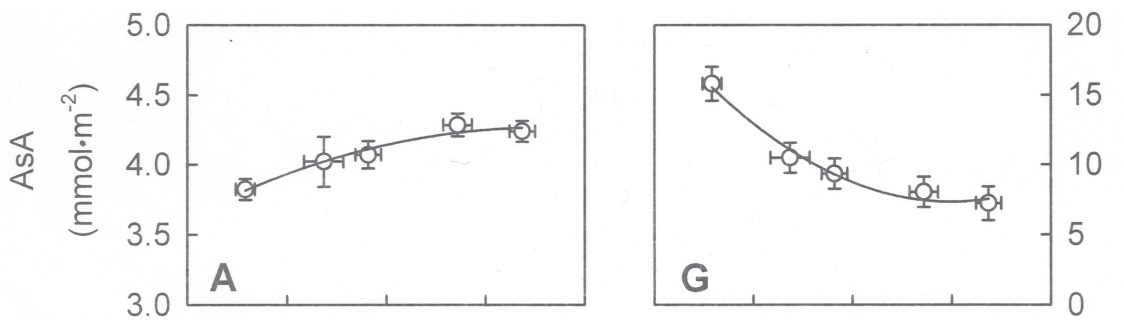

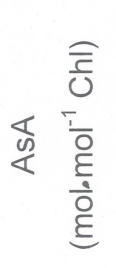
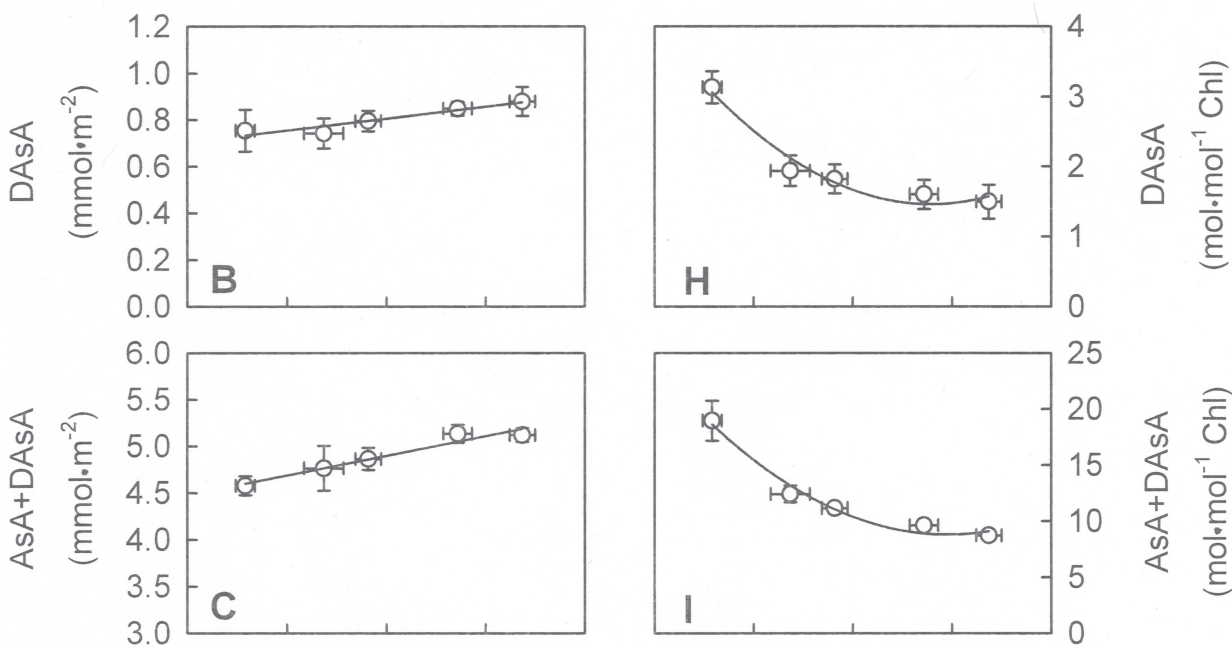

25

20
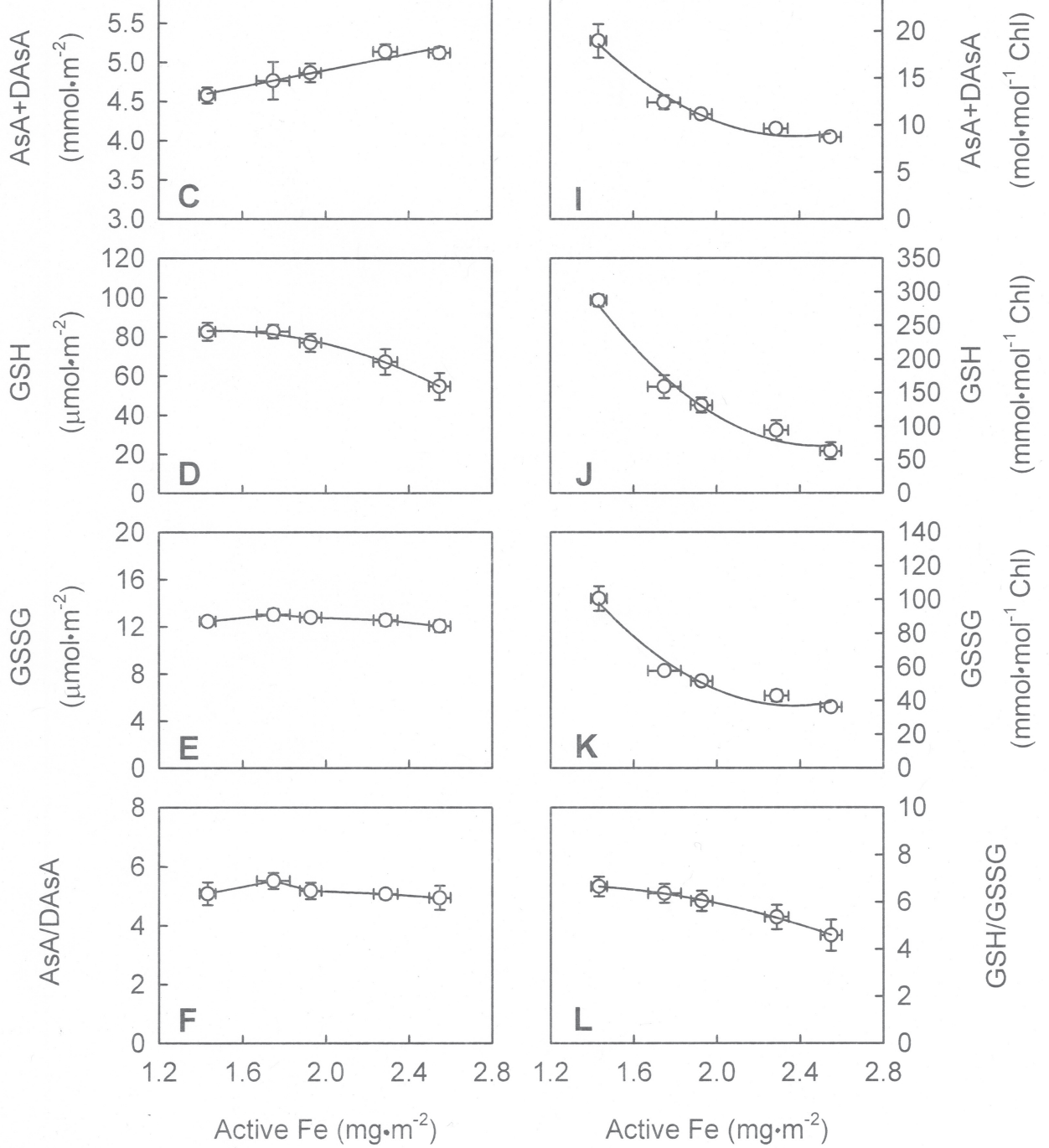

Fig. 8. Midday antioxidant metabolite content in relation to the active Fe content of grape leaves expressed on a leaf area or leaf Chl basis, respectively. (A, G) Reduced ascorbate (AsA); (B, H) dehydroascorbate (DAsA); (C, I) total ascorbate (AsA+DAsA); (D, J) reduced glutathione (GSH); (E, K) oxidized glutathione $(\mathrm{GSSG})$; (F) ratio of AsA/DAsA; (L) ratio of GSH/GSSG. Each point is mean \pm SE $(\mathrm{n}=3-5)$. Regression equations for $(\mathbf{A}) y=2.0769+1.6673 x-0.3176 x^{2}\left(r^{2}\right.$ $=0.960, P<0.05) ;($ B $) y=0.5495+0.1277 x\left(r^{2}=0.894, P<0.05\right) ;(\mathbf{C}) y=3.8464+0.5252 x\left(r^{2}=0.946, P<0.01\right) ;($ D $) y=26.7795+75.4270 x-25.3027 x^{2}\left(r^{2}\right.$ $=0.994, P<0.01)$; (E) $P>0.05$; (F) $P>0.05$; (G) $y=58.1709+42.4207 x-8.8477 x^{2}\left(r^{2}=0.982, P<0.05\right) ;(\mathbf{H}) y=12.4818-9.5224 x+2.0564 x^{2}\left(r^{2}=0.962\right.$, $P<0.05)$; (I) $y=70.6527-51.9431 x+10.9041 x^{2}\left(r^{2}=0.979, P<0.05\right) ;(\mathbf{J}) y=1230.6186-930.6434 x+186.6411 x^{2}\left(r^{2}=0.981, P<0.05\right) ;(\mathbf{K}) y=427.7990$ $-329.7703 x+69.5584 x^{2}\left(r^{2}=0.968, P<0.05\right) ;$ and $(\mathbf{L}) y=5.3095+2.4986 x-1.0899 x^{2}\left(r^{2}=0.999, P<0.001\right)$. 
such as chlorotic and necrotic specks on the foliage (Kampfenkel et al., 1995; Smith et al., 2004), and measured no decrease in $\mathrm{Chl}$ at the highest Fe levels (Fig. 2A). In fact, the vines grown at the highest $\mathrm{Fe}$ supply had the highest $\mathrm{CO}_{2}$ assimilation capacity (Chen et al., 2004). Fe overload has been associated with a lowered AsA/DAsA ratio (on a FW basis) and a doubling of APX and CAT specific activity in the leaves of Nicotiana plumbaginifolia Viv. (Kampfenkel et al., 1995). We found that many of the antioxidant enzymes and metabolites increased on a leaf area basis as active Fe increased, but when expressed on a Chl basis, we cannot conclude that the vines grown at high Fe levels suffered from Fe-catalyzed oxidative stress. $N P Q$ (calculated as $q \mathrm{NP}$ ) in N. plumbaginifolia also increased in response to $\mathrm{Fe}$ excess (Kampfenkel et al., 1995), yet we did not find an increase in $N P Q$ at the highest Fe level either.

In conclusion, both photoprotective mechanisms, xanthophyll cycle-dependent thermal dissipation and the antioxidant system, are enhanced in response to iron deficiency to cope with excess absorbed light. In a low soil $\mathrm{pH}$ tolerant species such as V. labruscana, the foliar antioxidant system was upregulated in response to excess absorbed light from Fe deficiency-induced chlorosis, and there was no evidence of an increase in oxidative stress from high rates of applied Fe-EDDHA.

\section{Literature Cited}

Abadía, J., E. Monge, L. Montanes, and L. Heras. 1984. Extraction of iron from plant leaves by iron II chelators. J. Plant Nutr. 7:777-784.

Abadía, J., F. Morales, and A. Abadía. 1999. Photosystem II efficiency in low chlorophyll, iron-deficient leaves. Plant Soil 215:183-192.

Alcaraz, C.F., E. Hellin, F. Sevilla, and F. Martinez-Sanchez. 1985. Influence of the leaf iron contents on the ferredoxin levels in citrus plants. J. Plant Nutr. 8:603-611.

Arnon, D.I. 1949. Copper enzymes in isolated chloroplasts. Polyphenoloxidase in Beta vulgaris. Plant Physiol. 24:1-15.

Asada, K. 1999. The water-water cycle in chloroplasts: Scavenging of active oxygens and dissipation of excess photons. Annu. Rev. Plant Physiol. Plant Mol. Biol. 50:601-639.

Baker, N.R., K. Oxborough, T. Lawson, and J.I.L. Morison. 2001. High resolution imaging of photosynthetic activities of tissues, cells and chloroplasts in leaves. J. Expt. Bot. 52:615-621.

Bavaresco, L., E. Giachino, and S. Pezzutto. 2003. Grapevine rootstock effects on lime-induced chlorosis, nutrient uptake, and source-sink relationships. J. Plant Nutr. 26:1451-1465.

Bienfait, H.F. 1987. Biochemical basis of iron efficiency reactions in plants, p. 339-349. In: G. Winkelmann, D. Van der Helm, and J.B. Neilands (eds.). Iron transport in microbes, plants, and animals. VCH, Weinheim, Fed. Rep. of Germany.

Bilger, W. and O. Björkman. 1990. Role of the xanthophyll cycle in photoprotection elucidated by measurements of light-induced absorbency changes, fluorescence and photosynthesis in leaves of Hedera canariensis. Photosyn. Res. 25:173-185.

Briat, J.F. 2002. Metal ion-activated oxidative stress and its control, p. 171-190. In: D. Inzé and M. Van Montagu (eds.). Oxidative stress in plants. Taylor \& Francis, London.

Brown, J.C. and W.E. Jones. 1976. Technique to determine iron efficiency in plants. Soil Sci. Soc. Amer. J. 40:398-405.

Brüggemann, W., K. Maaskantel, and P.R. Moog. 1993. Iron uptake by leaf mesophyll-cells - The role of the plasma membrane-bound ferric-chelate reductase. Planta 190:151-155.

Chaney, R.L. 1988. Recent progress and needed research in plant iron nutrition. J. Plant Nutr. 11:1589-1604.

Chaney, R.L., J.C. Brown, and L.O. Tiffin. 1972. Obligatory reduction of ferric chelates in iron uptake by soybean. Plant Physiol. 50:208-213.
Chen, L.-S., and L. Cheng. 2003. Both xanthophyll cycle-dependent thermal dissipation and the antioxidant system are up-regulated in grape (Vitis labrusca L. cv. Concord) leaves in response to $\mathrm{N}$ limitation. J. Expt. Bot. 54:2165-2175.

Chen, L.-S., B.R. Smith, and L. Cheng. 2004. $\mathrm{CO}_{2}$ assimilation, photosynthetic enzymes, and carbohydrates of 'Concord' grape leaves in response to iron supply. J. Amer. Soc. Hort. Sci. 129:738-744.

Cheng, L. 2003. Xanthophyll cycle pool size and composition in relation to the nitrogen content of apple leaves. J. Expt. Bot. 54:385-393.

Cheng, L., L.H. Fuchigami, and P.J. Breen. 2000. Light absorption and partitioning in relation to nitrogen content in 'Fuji' apple leaves. J. Amer. Soc. Hort. Sci. 125:581-587.

Davenport, J., R. Stevens, and K. Whitley. 2003. Occurrence of grape chlorosis in relation to soil and climate conditions. HortScience 38:795.

Demmig-Adams, B. and W.W. Adams. 1996. The role of xanthophyll cycle carotenoids in the protection of photosynthesis. Trends Plant Sci. 1:21-26.

Genty, B., J.M. Briantais, and N.R. Baker. 1989. The relationship between the quantum yield of photosynthetic electron transport and quenching of chlorophyll fluorescence. Biochimica et Biophysica Acta 990:87-92.

Gonzalez-Vallejo, E.B., F. Morales, L. Cistue, and A. Abadía. 2000. Iron deficiency decreases the Fe(III)-chelate reducing activity of leaf protoplasts. Plant Physiol. 122:337-344.

Griffith, O.W. 1980. Determination of glutathione and glutathione disulfide using glutathione reductase and 2-vinylpyridine. Anal. Biochem. 106:207-212.

Halliwell, B., and J.M.C. Gutteridge. 1984. Role of iron in oxygen radical reactions. Methods Enzymology 105:47-56.

Hossain, M.A., Y. Nakano, and K. Asada. 1984. Monodehydroascorbate reductase in spinach-chloroplasts and its participation in regeneration of ascorbate for scavenging hydrogen peroxide. Plant Cell Physiol. 25:385-395.

Iturbe-Ormaetxe, I., J.F. Moran, C. Arreseigor, Y. Gogorcena, R.V. Klucas, and M. Becana. 1995. Activated oxygen and antioxidant defenses in iron-deficient pea-plants. Plant Cell Environ. 18:421-429.

Jiang, C.D., H.Y. Gao, and Q. Zou. 2001. Enhanced thermal energy dissipation depending on xanthophyll cycle and D1 protein turnover in iron-deficient maize leaves under high irradiance. Photosynthetica 39:269-274

Jiang, C.D., H.Y. Gao, and Q. Zou. 2003. Changes of donor and acceptor side in photosystem 2 complex induced by iron deficiency in attached soybean and maize leaves. Photosynthetica 41:267-271.

Kampfenkel, K., M.M. Van, and D. Inzé. 1995. Effects of iron excess on Nicotiana plumbaginifolia plants: Implications to oxidative stress. Plant Physiol. 107:725-735.

Kochian, L.V. 1991. Mechanisms of micronutrient uptake and translocation in plants, p. 229-296, In: J. J. Mortvedt, F.R. Cox, L.M. Shuman, and R.M. Welch (eds.). Micronutrients in agriculture, 2nd ed. Soil Sci. Soc. America, Madison, Wis.

Li, X.P., A.M. Gilmore, S. Caffarri, R. Bassi, T. Golan, D. Kramer, and K.K. Niyogi. 2004. Regulation of photosynthetic light harvesting involves intrathylakoid lumen $\mathrm{pH}$ sensing by the PsbS protein. J. Biol. Chem. 279:22866-22874.

López-Millán, A.F., F. Morales, A. Abadiá, and J. Abadiá. 2001. Iron deficiency-associated changes in the composition of the leaf apoplastic fluid from field-grown pear (Pyrus communis L.) trees. J. Expt. Bot. 52:1489-1498.

Miller, G.W., I.J. Huang, G.W. Welkie, and J.C. Pushnik. 1995. Function of iron in plants with special emphasis on chloroplasts and photosynthetic activity, p. 19-28. In: J. Abadiá (ed.). Iron nutrition in soils and plants. Kluwer Academic, Boston.

Miyake, C. and K. Asada. 1994. Ferredoxin-dependent photoreduction of the monodehydroascorbate radical in spinach thylakoids. Plant Cell Physiol. 35:539-549.

Morales, F., A. Abadiá, and J. Abadiá. 1998. Photosynthesis, quenching 
of chlorophyll fluorescence and thermal energy dissipation in iron-deficient sugar beet leaves. Aust. J. Plant Physiol. 25:403-412.

Morales, F., A. Abadiá, R. Belkhodja, and J. Abadiá. 1994. Iron deficiency-induced changes in the photosynthetic pigment composition of field-grown pear (Pyrus communis L.) leaves. Plant Cell Environ. 17:1153-1160.

Morales, F., R. Belkhodja, A. Abadiá, and J. Abadiá. 2000. Photosystem II efficiency and mechanisms of energy dissipation in iron-deficient, fieldgrown pear trees (Pyrus communis L.). Photosyn. Res. 63:9-21.

Nakano, Y., and K. Asada. 1981. Hydrogen-Peroxide Is scavenged by ascorbate-specific peroxidase in spinach chloroplasts. Plant Cell Physiol. 22:867-880.

Niyogi, K.K. 2000. Safety valves for photosynthesis. Current Opinion Plant Biol. 3:455-460.

Niyogi, K.K., O. Björkman, and A.R. Grossman. 1997. The roles of specific xanthophylls in photoprotection. Proc. Natl. Acad. Sci. USA 94:14162-14167.

Noctor, G. and C.H. Foyer. 1998. Ascorbate and glutathione: Keeping active oxygen under control. Annu. Rev. Plant Physiol. Plant Mol. Biol. 49:249-279.

Oxborough, K. and N.R. Baker. 1997. Resolving chlorophyll a fluorescence images of photosynthetic efficiency into photochemical and non-photochemical components - Calculation of $\mathrm{qP}$ and $\mathrm{Fv}^{\prime} / \mathrm{Fm}^{\prime}$ without measuring Fo'. Photosyn. Res. 54:135-142.

Ranieri, A., A. Castagna, and G. Soldati. 1999. Iron deficiency induces variations in oxidative stress bioindicators in sunflower plants. Agricoltura Mediterranea 129:180-192.

Robinson, N.J., C.M. Procter, E.L. Connolly, and M.L. Guerinot. 1999. A ferric-chelate reductase for iron uptake from soils. Nature 397:694-697.

Römheld, V. 2000. The chlorosis paradox: Fe inactivation as a secondary event in chlorotic leaves of grapevine. J. Plant Nutr. 23:1629-1643.
Smith, B.R., P.R. Fisher, and W.R. Argo. 2004. Water-soluble fertilizer concentration and $\mathrm{pH}$ of a peat-based substrate affect growth, nutrient uptake, and chlorosis of container-grown seed geraniums. J. Plant Nutr. 27:497-524.

Spiller, S. and N. Terry. 1980. Limiting factors in photosynthesis .2. Iron stress diminishes photochemical capacity by reducing the number of photosynthetic units. Plant Physiol. 65:121-125.

Tagliavini, M. and A.D. Rombola. 2001. Iron deficiency and chlorosis in orchard and vineyard ecosystems. Euro. J. Agron. 15:71-92.

Tagliavini, M., J. Abadiá, A.D. Rombola, A. Abadiá, C. Tsipouridis, and B. Marangoni. 2000. Agronomic means for the control of iron deficiency chlorosis in deciduous fruit trees. J. Plant Nutr. 23:2007-2022.

Terry, N. 1983. Limiting factors in photosynthesis.4. Iron stress-mediated Cchanges in light harvesting and electron transport capacity and its effects on photosynthesis in vivo. Plant Physiol. 71:855-860.

Tiffin, L.O. 1970. Translocation of iron citrate and phosphorus in xylem exudate of soybean. Plant Physiol. 45:280-284.

van Kooten, O. and J.F.H. Snel. 1990. The use of chlorophyll fluorescence nomenclature in plant stress physiology. Photosyn. Res. 25:147-150.

Vert, G., N. Grotz, F. Dedaldechamp, F. Gaymard, M.L. Guerinot, J.F. Briat, and C. Curie. 2002. IRT1, an Arabidopsis transporter essential for iron uptake from the soil and for plant growth. Plant Cell 14:1223-1233.

Willekens, H., D. Inze, M. van Montagu, and W. van Camp. 1995. Catalase in plants. Mol. Breeding 1:207-228.

Winkler, A.J., J.A. Cook, W.M. Kliewer, and L.A. Lider. 1974. Fertilizer elements required by the vine, p. 410-434. In: General viticulture, Rev. and enl. ed. Univ. of California Press, Berkeley.

Zaharieva, T.B. and J. Abadiá. 2003. Iron deficiency enhances the levels of ascorbate, glutathione, and related enzymes in sugar beet roots. Protoplasma 221:269-275. 